\title{
O MESTRE IGNORANTE DE JACQUES RANCIÈRE: UM CAMINHO PARA APRENDIZAGEM DA FILOSOFIA NO ENSINO MÉDIO?
}

\author{
Suédson Relva Nogueira ${ }^{1}$ \\ José Teixeira Neto ${ }^{2}$
}

\begin{abstract}
Resumo:
O texto aqui apresentado é um recorte da dissertação intitulada "Igualdade e emancipação: signos para se pensar a avaliação em filosofia a partir de $O$ mestre ignorante de Jacques Rancière" defendida no Mestrado Profissional em Filosofia-PROF-FILO, Núcleo da Universidade do Estado do Rio Grande do Norte-UERN em junho 2020. Nesse recorte, a pesquisa parte da provocação de Ceppas (2013) segundo o qual há espaço na Escola para o "anúncio da boa nova da emancipação" e que tal anúncio, assumido pelo filósofo-professor, é um "desafio pedagógico-político". Ao assumir essa posição, a pesquisa questiona se é possível indicar um método para que o "anúncio da emancipação" na Escola possa ser feito segundo uma tonalidade inspirada em $O$ mestre ignorante? Em um primeiro momento, a pesquisa reconhece que existe uma discussão sobre o "método" na obra citada; que é possível indicar no texto diversas maneiras para se referir ao "método Jacotot" e que é possível também especificar elementos do referido "método". Porém, a pesquisa aponta restrições em $O$ mestre ignorante para uma "tradução pedagógica" ou institucionalização do "método Jacotot". Dessa forma, mais do que "criar" um novo método de aprendizagem da Filosofia, o objetivo do recorte que aqui apresentamos é indicar um caminho seguindo a narrativa da "experiência pedagógica" (RANCIÈRE, 2017, p. 32) de O mestre ignorante. Após a análise da bibliografia primária e secundária, a pesquisa apresenta oito passos ou movimentos para uma experiência com a Filosofia na Escola e, em sua última parte, amplia a discussão sobre o oitavo passo para pensar a avaliação da aprendizagem em Filosofia. Sobre esse último aspecto, a pesquisa conclui que se não cabe uma avaliação que verifique conhecimentos e conteúdos supostamente compreendidos ou não pelos estudantes, mas verificar o quanto o aluno buscou resolver a questão-problema colocada e como traduziu e deu palavra aos seus movimentos a partir da "coisa comum", na avaliação o mestre deveria verificar o quanto de "atenção" e "vontade" o estudante coloca na sua "busca".
\end{abstract}

Palavras-chave: Aprendizagem. Avaliação. Filosofia. Ensino Médio.

\section{JACQUES RANCIÈRE'S THE IGNORANT SCHOOLMASTER: A PATH TO PHILOSOPHY APPRENTICESHIP IN HIGH SCHOOL?}

\begin{abstract}
:
The text here presented is taken from the dissertation intitulated "Equality and emancipation: signs to think through the evaluation in philosophy based on Jacques Rancière's The Ignorant Schoolmaster", presented to the Professional Master's Programme in Philosophy - PROF-FILO, State University of Rio Grande do Norte (UERN) sector, in July 2020. Within such a framing, the enquiry begins from the provoking thought of Ceppas (2013), according to which there is place in schooling for the announcement of the Good News of emancipation", and that such an announcement, as assumed by the philosopher-teacher, is a "politico-paedagogical challenge". In assuming that standing, the enquiry asks whether it is possible to indicate a method so that the "announcement of emancipation" can be made according to a tonality inspired in The Ignorant Schoolmaster. In a first moment, the enquiry recognizes the existence of a discussion over the "method" in the aforementioned work; that it is possible to indicate within the text various manners of referring to the "Jacotot method", and that it is possible also to specify elements of the same method. However, the enquiry points to restrictions present in The Ignorant

\footnotetext{
${ }^{1}$ Professor da E. E. Professora Calpúrnia Caldas de Amorim-EECCAM (Caicó-RN). Mestre em Filosofia pela Universidade do Estado do Rio Grande do Norte-PROF-FILO/UERN (2020); graduado em História pela Universidade Federal do Rio Grande do Norte-UFRN (2017). E-mail: suedson.relva@ gmail.com

${ }^{2}$ Professor Adjunto IV, com dedicação exclusiva, da Universidade do Estado do Rio Grande do Norte-UERN, Curso de Filosofia do Campus Caicó-CaC. Doutor em Filosofia (UFRN-2012). Coordenador do Núcleo UERN do Mestrado Profissional em Filosofia - PROF-FILO. E-mail: joseteixeira@uern.br
} 
Schoolmaster to a "paedagogical translation" or an institutionalization of the "Jacotot method". Thence, rather than "creating" a new method for philosophy apprenticeship, the aim of the framing here presented is to indicate a path following The Ignorant Schoolmaster's narrative of "paedagogical experience" (RANCIÈRE, 2017, p. 32). After analysing both primary and secondary bibliographies, the enquiry introduces eight steps or movements toward an experience with philosophy in schools and, in its last part, it amplifies the discussion over the eighth step to think through the evaluation of philosophy apprenticeship. On this last aspect, the enquiry reaches the conclusion that, if an evaluation that verifies knowledges and contents supposedly understood or not by students is not fitting, but it should be verified how much has the student seeked to solve the problem-question given and how did she translate and give expression to her movements beginning from the "common thing", in evaluating the schoolmaster should verify how much of "attention" and "will" is put by the student in her "seeking".

Keywords: Apprenticeship. Evaluation. Philosophy. High school.

Na Escola há "[...] espaço para o anúncio da boa nova da emancipação". (CEPPAS, 2013, p. 100) e com esse mesmo autor, reconhecemos que esse anúncio é um "desafio pedagógico-político" que deve ser assumido também pelo filósofo, professor de Filosofia na Escola. A partir dessa posição, então, também podemos questionar: é possível indicar um método, procedimentos ou passos para que o "anúncio da emancipação" na Escola possa ser feito segundo uma tonalidade inspirada em $O$ mestre ignorante? A pergunta não é descabida de sentido. O termo "método" aparece diversas vezes em $O$ mestre ignorante tanto em um sentido mais geral, por exemplo, quando se afirma que a "inteligência superior" "procede por método" e busca "com método" (RANCIÈRE, 2017, p. 24-25) e mesmo quando, em diversos momentos, Rancière (2017, p. 32) está se referindo aos diversos métodos pedagógicos, tais como os "métodos duros ou suaves, tradicionais ou modernos, passivos ou ativos" (RANCIÈRE, 2017, p. 32).

Especificamente sobre um método próprio de Joseph Jacotot, encontramos diversas formas de nomeá-lo em $O$ mestre ignorante: "método da adivinhação" (RANCIÈRE, 2017, p. 28); "método do acaso" (RANCIÈRE, 2017, p. 30; 35, grifo do autor); "método da igualdade" e "método da vontade" (RANCIÈRE, 2017, p. 30, grifo do autor); "método do aluno" (RANCIÈRE, 2017, p. 32; 51); “o verdadeiro método" (RANCIÈRE, 2017, p. 36); “método Jacotot" ou o "método de Jacotot" (RANCIÈRE, 2017, p. 39; 51; 63; 91; 153; 159; 160; 185); "método emancipador" (RANCIÈRE, 2017, p. 64; 142); "Método Universal” (RANCIÈRE, 2017, p. 78; 109; 145); "Método do Ensino Universal" (RANCIÈRE, 2017, p. 102; 150); método fundado sobre a opinião da igualdade e da recusa das explicações (RANCIÈRE, 2017, p. 146); "o Ensino Universal” como "método natural do espírito humano" (RANCIÈRE, 2017, p. 147); “O Ensino Universal é o método dos pobres. Mas ele não é um método de pobres. É um método de homens, isto é, de inventores”. (RANCIÈRE, 2017, p. 147, grifo do autor). Esse "método", por outro lado, se diferencia do "Velho método" (RANCIÈRE, 2017, p. 143-144), 
aquele da "explicação" (RANCIÈRE, 2017, p. 30); "difere radicalmente do método do mestre socrático" (RANCIÈRE, 2017, p. 51-52); com relação aos métodos pedagógicos de então, era considerado "método maldito" (RANCIÈRE, 2017, p. 28); "método mau" que "Os metodistas opõem [...] ao caminho da razão" (RANCIÈRE, 2017, p. 28); “estranho método" (RANCIÈRE, 2017, p. 96). Por fim, segundo Rancière (RANCIÈRE, 2017, p. 178), “Todos se unem [...] para rejeitar o único método que não é bom, o método funesto, isto é, o método da má emancipação, o método - o anti-método - Jacotot".

Podemos também tentar especificar alguns elementos do "método Jacotot": é um "método" que pode ser verificado na "[...] experiência da criança, do sábio e do revolucionário" e que revela, a partir das experiências dos "estudantes flamengos" que se pode "[...] aprender sozinho, e sem mestre explicador, quando se queira, pela tensão de seu próprio desejo ou pelas contingências da situação." (RANCIÈRE, 2017, p. 30); é o “[...] verdadeiro método pelo qual cada um aprende e pelo qual cada um descobre a medida de sua capacidade". (RANCIÈRE, 2017, p. 36). Esse método não pode ser comparado com a "prática dos pedagogos" que "se apóia (sic.) na oposição da ciência e da ignorância" e "se distinguem pelos meios escolhidos para tornar sábio o ignorante" (RANCIÈRE, 2017, p. 32), o "método emancipador" se apoia na “igualdade das inteligências"; nesse sentido, "O 'método Jacotot' não é melhor, é diferente. Por isso, os procedimentos colocados em prática importam pouco, neles mesmos." (RANCIÈRE, 2017, p. 49); além disso, não era um método de instrução do povo, mas tratava-se “[...] da graça a ser anunciada aos pobres: eles podiam tudo o que pode um homem. Bastava anunciar. Jacotot decidiu consagrar-se a isso." (RANCIÈRE, 2017, p. 38) e, por fim, também destacamos o "cerne" desse método: "Para emancipar a outrem, é preciso que se tenha emancipado a si próprio." (RANCIÈRE, 2017, p. 57).

Porém, para Rancière (2017, p. 36):

Este é, no entanto, o salto mais difícil. Quando necessário, todos praticam esse método, mas ninguém está pronto a reconhecê-lo, ninguém quer enfrentar a revolução intelectual que ele implica. O círculo social, a ordem das coisas, proíbe que ele seja reconhecido pelo que é: o verdadeiro método pelo qual cada um aprende e pelo qual cada um descobre a medida de sua capacidade.

Rancière (2017, p. 51-52, grifo do autor) sugere "dois atos fundamentais do mestre": "provocar" uma inteligência e "verificar" o trabalho dessa inteligência. Assim, podemos sugerir o que pode o mestre ignorante ao "se utilizar" do "método emancipador" e como o que faz o diferencia do mestre explicador: 
[...] ele interroga, provoca uma palavra, isto é, a manifestação de uma inteligência que se ignorava a si própria, ou se descuidava. Ele verifica que o trabalho dessa inteligência se faz com atenção, que essa palavra não diz qualquer coisa para se subtrair à coerção. Dir-se-á que, para isso, é preciso um mestre muito hábil e muito sábio? Ao contrário, a ciência do mestre sábio torna muito difícil para ele não arruinar o método. Conhecendo as respostas, suas perguntas para elas orientam naturalmente o aluno. É o segredo dos bons mestres: com suas perguntas, eles guiam discretamente a inteligência do aluno - tão discretamente, que a fazem trabalhar, mas não o suficiente para abandoná-la a si mesma. Há um Sócrates adormecido em cada explicador. E é preciso admitir que o método Jacotot — isso é, o método do aluno difere radicalmente do método do mestre socrático.

Pareceria, então, que está tudo explicado. Temos um "método Jacotot"; sabemos quais são as suas características fundamentais; compreendemos que esse método se diferencia dos outros métodos pedagógicos, embora não possa ser comparado com eles, pois o que existe entre o "método Jacotot" e os outros métodos é uma diferença de princípio. Por fim, concordamos com Ceppas (2013) que a Escola pode ser um espaço para "o anúncio da boa nova emancipadora". Existem, porém, algumas restrições em $O$ mestre ignorante ao que se poderia chamar "tradução pedagógica" ou institucionalização do "método Jacotot".

Cabe lembrar, em primeiro lugar, que o "método Jacotot" não é um método de instrução do povo. Rancière (2017, p. 12), é bastante claro no Prefácio à edição brasileira ao afirmar que "Os amigos da igualdade não têm que instruir o povo, para aproximá-lo da igualdade, eles têm que emancipar as inteligências, têm que obrigar a quem quer que seja a verificar a igualdade de inteligências". Isso significava anunciar aos pobres que "[...] eles podiam tudo o que pode um homem”. (RANCIÈRE, 2017, p. 38). Ainda no Prefácio, Rancière (2017, p. 12) esclarece que essa é uma questão "propriamente filosófica" e uma "questão política" e que "Não se trata de uma questão de método, no sentido de formas particulares de aprendizagem”. A questão filosófica é “[...] saber se o ato mesmo de receber a palavra do mestre — a palavra do outro - é um testemunho de igualdade ou de desigualdade" e a questão política é ' [...] saber se o sistema de ensino tem por pressuposto uma desigualdade a ser 'reduzida', ou uma igualdade a ser verificada".

Rancière (2017, p. 143, grifo do autor) também lembra que quando o Príncipe Frederick, filho do Rei dos Países Baixos, “[...] convenceu [...] seu pai a criar em Louvain uma Escola Normal Militar, cuja responsabilidade pedagógica foi confiada a Jacotot", a experiência não vingou, pois embora "a intenção" fosse boa, “[...] o presente era de grego: Jacotot era um mestre, não um dirigente. Seu método era próprio para formar homens emancipados, mas não instrutores militares, ou sequer servidores em qualquer especialidade social”. Dois outros

\begin{tabular}{|c|c|c|c|c|}
\hline Qonita Dialectus & Ano 9 & n. 20 & Outubro - Novembro 2020 & p. $133-153$ \\
\hline
\end{tabular}


aspectos nessa questão também chamam a nossa atenção: “Um Ensino Universal, contudo, não pode, sem se deturpar especializar-se na produção de uma categoria determinada de atores sociais [...]" e que "O Ensino universal pertence às famílias [...]”. Nesse sentido, não poderíamos "utilizar" o "método Jacotot" para formar, por exemplo, "bons cidadãos”, críticos dos aparatos políticos e conhecedores de seus deveres.

Dessa forma, para Rancière (2017, p. 147), por um lado, “[...] o Ensino Universal não vingará, ele não se estabelecerá na sociedade”. Porém, ele também “[...] não morrerá, porque é o método natural do espírito humano, o de todos os homens que buscam seu próprio caminho". Podemos dizer, portanto, que Jacotot também recusa a institucionalização do seu “método", pois, como explicita Rancière (2017, p. 146, grifo do autor), “Toda instituição é uma explicação em ato da sociedade, uma encenação da desigualdade. Seu princípio é e será sempre antitético ao do método fundado sobre a opinião da igualdade e da recusa das explicações". Por fim, cabe lembrar que para Rancière (2017, p. 184. Grifo do autor):

Jacotot foi o único igualitário a perceber que a representação e a institucionalização do progresso acarretavam a renúncia à aventura intelectual e moral da igualdade e que a instrução pública era o trabalho do luto da emancipação. Um saber dessa ordem provoca uma horrorosa solidão. Jacotot acostumou-se a essa solidão. Rejeitou qualquer tradução pedagógica e progressista da igualdade emancipadora.

A partir desses pressupostos, perguntamo-nos, então: O que $O$ mestre ignorante nos oferece para pensar uma aprendizagem da Filosofia? De modo geral, essa aprendizagem deve ser emancipatória e se sustentar no princípio e na opinião da igualdade de inteligências; deve ser uma aprendizagem que se sustente numa atitude emancipadora do mestre e que busca verificar essa mesma atitude nos estudantes; que estimula as potências intelectuais dos estudantes; que não se utiliza de caminhos que primem por atitudes mecânicas e hierarquizadas e, por fim, que não conduza o estudante para que ao final do percurso assuma e ocupe papéis sociais previamente estabelecidos. Repensar a aprendizagem da Filosofia na Escola a partir de $O$ mestre ignorante, por fim, não se reduziria a elaborar algumas regras para uma didática filosófica e pôr em prática um método específico de ensino. Podemos repetir que o "método Jacotot" é o "método do aluno" e, por isso, um primeiro aspecto, exige que desviemos o foco do ensino para a aprendizagem e do mestre para o estudante ${ }^{3}$.

\footnotetext{
3 Isso não significa também negar a necessidade de pensar uma didática específica para o ensino de filosofia. Boavida (1996) relata que pretendendo realmente um ensino de Filosofia voltado para a profundidade da própria Filosofia se deve sair da chamada didática clássica, voltada para a simplicidade da transmissão e exposição, para, desde de já, partir para uma didática específica da Filosofia. Sem essa mudança de foco a Filosofia certamente

\begin{tabular}{|c|c|c|c|c|}
\hline$\sigma$ & Ano 9 & n. 20 & Outubro - Novembro 2020 & p. $133-153$ \\
\hline
\end{tabular}
}


Rancière (2017, p. 19) relata que em grande parte de sua vida educacional Jacotot fora cuidadoso, organizado e pragmático e que era um professor "consciencioso" e que sabia que educar “[...] não se tratava de entupir os alunos de conhecimentos, fazendo-os repetir como papagaios, mas, também, que é preciso evitar esses caminhos do acaso [...]”. A mudança de postura emerge no instante em que Jacotot vive uma experiência pedagógica inusitada e fortuita no encontro que tivera com os estudantes flamengos: "Ele não lhes havia explicado a ortografia e as conjunções. Sozinhos, eles haviam buscado as palavras francesas correspondentes àquelas que conheciam [...]" (RANCIÈRE, 2017, p. 20). Sem nenhuma ajuda, desvendaram os segredos da edição bilíngue do Telêmaco e Jacotot descobria a potência intelectual e individual presente em cada um deles. A partir de então, Jacotot posiciona seu método, ou melhor, seu modo de fazer, como uma atitude particular, que pode conduzir os indivíduos à "emancipação intelectual".

Marques et al. (2018) também não acreditam na utilidade para o ensino de Filosofia da concepção clássica de método ${ }^{4}$. Para Marques et al. (2018, p. 8) tratar-se-ia de uma "[...] filosofia atenta às vidas e experiências ordinárias, indagando, respectivamente, pelas suas dimensões de liberdade e resistência; emancipação e subjetivação política". Não se trata, portanto, de "[...] expor um método como um conjunto de procedimentos técnicos, mas ao revés, exigir que um método seja um princípio de ação, uma experiência em si, uma posição subjetiva" (MARQUES et al. 2018, p. 10). Nesse sentido, como dizem Cruz et al. (2017), tratase de uma experiência individual e singular de aprender o que assim quiser, a partir da força da própria vontade, sempre impulsionada pela premissa e, sobretudo, pela consciência de que todos os homens possuem igual capacidade de aprender sozinhos. Tratar-se de uma ação de descontinuidade com o que é dado, uma proposta de reorganizar os conceitos e signos que enquadram cada indivíduo e que os aprisiona. A manifestação da igualdade, ou melhor, a verificação da "igualdade de inteligência" dá aos indivíduos a qualidade necessária para perceber o que é dado. De fato, não se trata, simplesmente de novas experiências, mas de saber ler as que já se apresentam no cotidiano: “O método, nessa perspectiva, é um ato de

se manterá, como acontece, restrita a alguns poucos catedráticos. Ainda para Boavida (1996, p. 101), “O como ensinar e aprender deveria, pois, em filosofia, exigir, pela sua natureza, uma indagação, um debate e uma pesquisa, os quais implicariam uma prática nova. Ou, inversamente, uma prática nova em virtude do debate e da pesquisa reflectir-se-ia numa nova concepção de filosofia".

4 Segundo o Dicionário de Filosofia Nicola Abbagnano (2000), a palavra método tem dois significados: no primeiro significado não prevê distinção entre "investigação" e "doutrina”. O conceito do segundo é mais restrito e indica um procedimento de investigação apurado e organizado, receptível e autocorrigível, que garanta a obtenção de resultados válidos. Dos dois, esse último é o mais praticado hoje em dia pelos pesquisadores.

\begin{tabular}{|c|c|c|c|c|}
\hline Qonista Dialectus & Ano 9 & n. 20 & Outubro - Novembro 2020 & p. $133-153$ \\
\hline
\end{tabular}


desconstrução e desclassificação que não se alia a uma suposição de ciência aplicada" (MARQUES et al., 2018, p. 17).

Até aqui, questionamos se era possível pensar em um caminho para a aprendizagem de Filosofia na Escola a partir de $O$ mestre ignorante. Em vez de um método começamos a falar em passos, movimentos e atitudes para uma aprendizagem emancipatória da Filosofia e, portanto, passos que primem por se desviar da mecanização e da hierarquização; que não necessitem de um sistema estruturado e bem organizado e constituído de mestres explicadores; que valorizem a autonomia e impulsionem a vontade dos estudantes e que leve a uma aprendizagem que parta do princípio de uma ação, de uma atitude que possa possibilitar a emancipação das personagens da ação educacional. Nessa visão, diferente de um método, procuramos sugerir oito passos e movimentos para uma experiência com a Filosofia na Escola. Apresentamos a seguir oito passos que imaginamos; outros passos podem ser imaginados e inventados. Esses recobrem o que aprendemos com Rancière/Jacotot.

O primeiro passo para uma aprendizagem emancipatória da Filosofia é a necessidade de partirmos da igualdade e da emancipação intelectual. Porém, devemos deixar de lado a ideia de igualdade projetada como meta a ser alcançada, que estabelece a hierarquização entre os indivíduos, e pensar a igualdade de inteligências como uma "opinião" (RANCIÈRE, 2017, p. 71), um “princípio" (RANCIÈRE, 2017, p. 50) ou uma "suposição" (RANCIÈRE, 2017, p. 72) “a ser verificada” (2017, p. 12; 100; 107) em cada homem ou mulher. Para Rancière (2017), quando se parte da ideia de que não existe igualdade entre os homens, perpetua-se o desequilíbrio pujante entre as capacidades intelectuais e solidifica-se o estado de embrutecimento. No contexto de uma sala de aula, partir da igualdade como princípio da ação educativa, é deixar claro para as personagens que lá estão que todos podem e devem manifestar suas capacidades intelectuais sem se preocupar com julgamentos, classificações ou postos hierárquicos: "Esse gesto inicial de igualdade abre as portas para a razão na medida em que ninguém acredita ser o seu dono" (KOHAN, 2005, p. 199).

Seguindo Rancière (2017), o segundo e terceiro passos, respectivamente, dizem respeito à exigência de ruptura com a lógica da explicação e do mestre explicador e, em seguida, à condição de uma reorientação do papel do mestre na aprendizagem de Filosofia. Desenraizar a ideia de um mestre explicador é uma tarefa difícil no contexto cultural contemporâneo, já que se mantém atualmente a prerrogativa de que a função de um mestre é transmitir o que sabe para aqueles que ainda não sabem. Nessa perspectiva, quem explica estrutura, condiciona e limita o que deve ou não ser ensinado; no dizer de Kohan (2005, p. 189) “[...] é juiz e parte da 
explicação, o único que sabe e, ao mesmo tempo, legitima seu saber”; dita as regras do aprender, estabelece os parâmetros mínimos para a ascensão educacional. O mestre torna-se um agente replicador das diretrizes do sistema político vigente, e a escola o seu lugar de atuação: “O explicador é aquele que impõe e abole a distância, que a desdobra e que a reabsorve no seio de sua palavra" (RANCIÈRE, 2017, p. 22). O mestre explicador estabelece a estrutura do aprendizado, separa e organiza o que deve ser ensinado e aprendido e rotula e hierarquiza os que compreendem e os que não compreendem. Por outro lado, o mestre que ignora será aquele que irá apresentar as várias possibilidades de caminhar e estimular as vontades dos estudantes.

Para propiciar uma aprendizagem emancipadora, é necessário que o mestre faça o movimento e saia da posição de detentor de uma ciência forçosamente necessária e se coloque no ambiente de aprendizagem como mais um aprendiz. Na entrevista sobre a atualidade do mestre ignorante, Rancière (2003) afirma que existem duas dimensões a serem observadas na ignorância do mestre e uma delas é a possibilidade de o mestre retirar-se "empiricamente do jogo" e essa dimensão é acentuada quando “[...] o mestre realmente ignora o que o aluno deve aprender" (RANCIÈRE, 2003, p. 192). É preciso que se desfaça de seu personagem de sabedor e se mostre receptivo a perceber as experiências de uma aprendizagem conjunta. É primordial que o mestre fique atento ao estudante e que possa estar aberto ao imponderável e inesperado que pode vir das vivencias, das incertezas, angústias e desejos do estudante. Cabe sempre lembrar que isso não exclui ou elimina a importância do mestre no processo de ensinoaprendizagem de Filosofia, mas, reorienta o papel fundamental do mestre na educação filosófica. Ao invés de um mestre explicador, teremos um mestre emancipador.

O quarto passo será estabelecer o papel do mestre nessa experiência de aprendizagem. Não existe espaço para um mestre que apenas explica, transmite sua irrefutável ciência. Ora, se a transmissão de conhecimento não basta como prerrogativa de um mestre, então qual seria a função do mestre na aprendizagem de Filosofia? Cerletti (2003) acena que a função do mestre é colocar desafios, problematizar o mundo e o estudante deve solucionar por si mesmo as questões que lhe são apresentadas. Além disso, para Cerletti $(2009$, p. 80) "Ensinar é colocar alguém na antessala de desafios que, em última instância, são pessoais". Caberia ao professor de Filosofia, alerta ainda Cerletti (2009, p. 80), “[...] estimular a levar adiante esse desafio. Filosofar é atreve-se a pensar por si mesmo, e fazê-lo requer uma decisão".

O mestre deve agir como o educador Jacotot um dia fez, "[...] ele indicou a obra aos estudantes e lhes solicitou que aprendessem, amparados pela tradução, o texto em francês" (RANCIÈRE, 2017, p. 18). O mestre deve a todo tempo provocar os estudantes, incitá-los a se 
permitir experiências. O mestre também deve participar da ação promotora de saberes, desta vez não como um juiz intransigente, mas como partícipe afetivo da experiência educativa. $\mathrm{O}$ docente deve poder criar "[...] condições para que os estudantes possam tornar própria uma forma de interrogar e uma vontade de saber" (CERLETTI, 2009, p. 37) 5 .

Segundo Rancière (2017), o "velho método" exige a efetiva participação de um mestre que explique a ciência dos livros para os estudantes. Por sua vez, na experiência de Jacotot, o mestre não teria essa prerrogativa de transmitir os saberes nem seria interlocutor ou tradutor dos textos para os estudantes. De fato, Rancière (2017) rejeita a necessidade de um mestre explicador, mas não a necessidade de um mestre. Ele percebe a importância de um mestre que não se volta para a explicação, que pode ser qualquer um e não precisa ensinar nada de sua ciência. Como dito, o mestre estaria muito mais para influenciador de vontades, um provocador de atitudes, essa seria a função do mestre que emancipa para Jacotot e nessa perspectiva podemos falar de uma inversão na relação mestre-aluno: de uma relação verticalizada para uma relação horizontal.

Cerletti (2003) chama de "educação verticalizada" um ensino estruturado de cima para baixo. Nessa lógica, impõe-se um modelo sócio educacional e, principalmente, político, pautado em uma hierarquização exacerbada que estabelece que existem superiores e inferiores, princípio da desigualdade e embrutecimento das pessoas. Por sua vez, na relação horizontal se reconhece em todos a mesma capacidade intelectual de aprender. Em uma aula de Filosofia, por exemplo, se reconhece que todos podem contribuir para a experiência filosófica, caminho para a "emancipação intelectual” que, segundo Kohan (2005, p. 199), abre “[...] as portas para o aprender, na medida em que só um igual compreende um igual”.

O quinto passo diz respeito a estabelecer uma questão problema e da "coisa comum". Deve-se pensar em um problema que abranja a todos, inclusive o mestre. Por exemplo, poderia ser: o que é Filosofia? O que é filosofar? Por que ensinar Filosofia? Por que aprender Filosofia? Qual é a utilidade do ensino de Filosofia? O que é a escola? O que significa avaliar e ser avaliado? Qual a importância disso para a aprendizagem? São propostas de problemáticas que se poderia apresentar para uma deliberação conjunta. Quanto a esse passo, podemos acrescentar com Cerletti (2009, p. 83) que se o ensino de Filosofia deve ser filosófico,

\footnotetext{
5 Em uma aula de Filosofia no Ensino Médio, por exemplo, uma indicação seria levar um esquema simples, segundo Cerletti (2009, p. 84), composto por: [...] (problematização - tentativa de resolução - nova problematização compartilhada - nova tentativa de resolução - ...) é formal e aberta, uma vez que não indica o 'que/como' ensinar (em um sentido específico) nem como avaliar o acontecido em um curso. Cada professor atualizará ou 'encarnará' em cada curso uma proposta concreta de problemas e uma tentativa de revolvê-los.

\begin{tabular}{|l|l|l|l|l|}
\hline Q & Anoista 9 & n. 20 & Outubro - Novembro 2020 & p. $133-153$ \\
\hline
\end{tabular}
}


então caberá ao professor “[...] ser um filósofo que cria e recria cotidianamente um conjunto de problemas filosóficos e suas tentativas de resposta, e isso ele não fará sozinho, mas com seus alunos". Após a escolha da questão-problema a ser trabalhada em sala, estabelece-se um laço mínimo entre os participantes da experiência educacional, a "coisa comum" (RANCIÈRE, 2017). Por exemplo, uma obra literária que tenha significado para todos os personagens do filosofar e que possa propiciar a discussão acerca da questão problema formulada. Os “[...] textos filosóficos serão uma ferramenta central para o filosofar, mas não um fim em si mesmo" (CERLETTI, 2009, p. 81). Em Rancière (2017), o ato de escrever e a ação de ler possuem, ambos, valor igualitário. Ora, a relação direta com a "coisa comum", que Cerletti (2003) chama de "ferramenta motor", pode ressignificar as palavras em um contexto no qual não existe um emissor legítimo (um detentor de conhecimento) e um receptor específico (aquele que não detém o conhecimento). Para Marques et al. (2018, p. 24), "Isso seria a democracia para Rancière, ou seja, o desenraizamento das palavras de uma plataforma que separa aqueles que podem e não podem ter acesso aos sentidos, promovendo uma abertura de acesso a todos".

O sexto passo trata do estímulo dado aos estudantes. O propósito do professor como mestre que ignora será o de sempre pôr essas questões aos estudantes: "O que veem?"; "O que estão a pensar sobre isso?" e "O que fariam a respeito?". O mestre trabalha e discute com os estudantes o problema a partir da base teórica contida na "coisa comum" em uma perspectiva de diálogo entre os saberes individuais e a "coisa comum". Em todo o processo, devemos sempre afirmar aos estudantes que eles podem aprender o que assim desejarem.

Para Cerletti (2003, p. 303, grifos do autor, tradução nossa) ${ }^{6}$,

O mestre não deve parar de perguntar: 'e você ... o que você vê? O que você acha? O que você faria?' As respostas, então, deixarão de ser um segredo valorizado pelo professor para se tornar uma conquista, de cada aluno, de conhecimento, do mundo e de si mesmo. O único imperativo que o mestre deve sustentar com tenacidade diante de um aluno é 'você pode!'. Partindo deste slogan, que potencializa as possibilidades de cada um, juntamente com as três questões mencionadas, é possível deslocar a questão educacional para a política e avaliar suas consequências. Na verdade, alguém que não se submete a uma ordem hierárquica, construído a partir das desigualdades de inteligência ou outra referência, alguém que não é visto como inferior, mas

\footnotetext{
6 “El maestro no debe dejar de preguntar: ‘y tú... ¿qué ves?, ¿qué piensas?, ¿qué harías?’. Las respuestas, entonces, dejarán de ser un secreto que atesora el maestro para transformarse en una conquista, de cada alumno, sobre los saberes, sobre el mundo y sobre sí mismo. El único imperativo que el maestro debe sostener con tenacidad frente a un alumno es ‘itú puedes!'. Partiendo de esta consigna, que potencia las posibilidades de cada uno, junto a los tres interrogantes mencionados, es posible desplazar la cuestión educativa hacia la política y evaluar sus consecuencias. En efecto, alguien que no se somete a un orden jerárquico, construido a partir de desigualdades de inteligencia u otra referencia, alguien que no se ve como inferior, sino que reconoce y valora su propia capacidad, y se sostiene en su tenacidad, podrá emanciparse”. (CERLETTI, 2003, p. 303).
}

\begin{tabular}{|c|c|c|c|c|}
\hline Revita Dialectus & Ano 9 & n. 20 & Outubro - Novembro 2020 & p. $133-153$ \\
\hline
\end{tabular}


reconhece e valoriza a sua própria capacidade, e realizada em sua tenacidade, pode emancipar.

Nessas ideias apontadas anteriormente, podemos perceber, além de uma questão de aprendizagem e ensino, concepções políticas envolvidas nesse processo de emancipação proposto por Rancière (2017). Portanto, não se trata de ensinar o que se acredita saber em termos de conhecimento quantitativo e que se pensa ser necessário que os estudantes saibam. A indicação aqui proposta é estimular movimentos individuais, ações particulares que busquem enxergar as experiências que aí estão por força de sua própria vontade. Segundo Cerletti (2003), deve-se falar muito mais de uma atitude intelectual por parte do estudante, fortemente estimulado pelo mestre, que o leva a se tornar protagonista de sua própria história. Nesse caso, o "[...] que é ensinado, quando emancipado, é usar a própria inteligência” (CERLETTI, 2003, p. 302).

O sétimo passo é retirar do vocabulário do ensino-aprendizagem como um todo e, em especial, no ensino de Filosofia, o verbo “compreender" e o que ele implica. Quando é usado, automaticamente, implanta-se a dicotomia entre os mundos dos que sabem e os que almejam saber. Na ordem das explicações, antes de dizê-lo existe a prerrogativa de uma explicação sobre a ordem das coisas. Seguindo essa linha, existe a necessidade contínua de um explicador sistemático e repositor de códigos e signos previamente estabelecidos e imutáveis.

Afirma Rancière (2017, p. 25, grifo do autor):

Infelizmente, é essa pequena palavra, exatamente essa palavra de ordem dos esclarecidos - compreender - a causadora de todo o mal. É ela que interrompe o movimento da razão, destrói sua confiança em si, expulsa-a de sua via própria, ao quebrar em dois o mundo da inteligência, ao instaurar a ruptura entre o animal que tateia e o pequeno cavalheiro instruído, entre o senso-comum e a ciência. A partir do momento em que se pronuncia essa palavra de ordem da dualidade, todo aperfeiçoamento na maneira de fazer compreender - essa grande preocupação dos metodistas e dos progressistas - se torna um progresso no embrutecimento.

Antes de anunciar o oitavo e último passo, cabe lembrar que na ordem explicadora, o mestre avalia o quanto o estudante aprendeu de sua ciência, quanto de conteúdo foi capaz absorver do que lhe fora transmitido por meio da explicação. Nessa perspectiva, o peso maior é dado a uma prova individual escrita e sem consulta e que no final do curso avalia o quanto de conteúdo o estudante foi capaz de reter. Como, então, avaliar em Filosofia a partir de uma proposta de aprendizagem que parta das indicações de $O$ mestre ignorante? Primeiramente, parece que a avaliação deveria ser orientada inicialmente pela afirmação segundo a qual o sábio 
julga “[...] os resultados do trabalho, para verificar a ciência do aluno. O ignorante, por sua vez, fará menos e mais, ao mesmo tempo. Ele não verificará o que o aluno descobriu, verificará se ele buscou" (RANCIÈRE, 2017, p. 53-54). Portanto, tratar-se-ia de "verificar" buscas, movimentos, deslocamentos e não "conhecimentos".

Uma avaliação-verificação filosófica que se constrói a partir dos signos de "igualdade de inteligência" e "emancipação intelectual" de $O$ mestre ignorante necessitaria concretizar, que se pudesse transpor a lógica conteudista e cientificista que direciona a avaliação para a quantidade de ciência adquirida. Na perspectiva de $O$ mestre ignorante, verifica-se o movimento, a ação, a atitude perante às questões-problema que se apresentam; verifica-se o processo da emancipação intelectual, o apoderamento e a busca feita pelos estudantes para aprender e traduzir os signos do mundo a partir de seu próprio olhar. Nessa perspectiva, portanto, a avaliação-verificação da aprendizagem da Filosofia não corresponderia mais a verificar se o estudante sabe o que o mestre disse ou o que disse um filósofo, mas avaliarverificar é ouvir o aluno, pois o mestre se interessa pela sua palavra, pois a palavra do estudante responde a uma palavra humana que lhe foi dirigida:

A criança que repete as palavras aprendidas e o estudante flamengo 'perdido' em seu Telêmaco não se guiam pelo acaso. Todo o seu esforço, toda a sua exploração é tencionada pelo seguinte: uma palavra humana lhes foi dirigida, a qual querem reconhecer e à qual querem responder - não na qualidade de alunos, ou de sábios, mas na condição de homens; como si responde a alguém que vos fala, e não a quem vos examina: sob o signo da igualdade. (RANCIÈRE, 2017, p. 29).

O professor de Filosofia que tem, por exemplo, o livro didático como ferramentamotor ou "coisa comum", deve verificar se o estudante consegue sozinho eliminar a distância entre ele e os raciocínios do livro. Deve verificar, no contexto do ensino de Filosofia, o quanto o estudante se aproximou e foi modificado pelas experiências filosóficas propostas em sala de aula, como enquanto emancipado traduz o cotidiano sociocultural e, em especial, político. Se não cabe uma avaliação que verifique conhecimentos e conteúdos supostamente compreendidos ou não pelos estudantes, mas verificar o quanto o aluno buscou resolver a questão-problema colocada e como traduziu e deu palavra aos seus movimentos a partir da "coisa comum", cabe então perguntar, a quais aspectos o mestre deve estar atento para verificar se se trata de uma "busca" que se dá sob o signo da igualdade e da emancipação? A partir de $O$ mestre ignorante parece necessário que o professor esteja atento a "busca", "vontade" e a "atenção" que o estudante coloca na procura por tentar decifrar os signos do mundo.

Rancière (2017, p. 83, grifo do autor) afirma que,

\begin{tabular}{|l|l|l|l|l|}
\hline Govista Dialeatus & Ano 9 & n. 20 & Outubro - Novembro 2020 & p. $133-153$ \\
\hline
\end{tabular}


[...] a vontade, reencontra sua racionalidade no seio do espaço de cada um sobre si mesmo, da autodeterminação do espírito como atividade. A inteligência é atenção e busca, antes de ser combinação de ideias. A vontade é potência de se mover, de agir segundo movimento próprio, antes de ser instância de escolha.

A "atenção" é o ato de impulsionar, por força da vontade, uma inteligência ligada ao sistema explicador. A "atenção" se manifesta como o poder de perceber e compreender o que se vê e o que se fala e de relacionar todos os nossos signos com os signos do mundo que se mostram à nossa frente: "Não há senão um poder, o de ver e de dizer, de prestar atenção ao que se vê e ao que se diz." (RANCIÈRE, 2017, p. 47).

Há, para Rancière (2017), duas ações fundamentais que o mestre ignorante não deve deixar de fazer: a primeira, é sempre provocar a inteligência do estudante, não guiar, mas interrogar sobre as suas percepções dos signos do mundo; a segunda, deve verificar se o estudante está colocando "atenção" em todo o percurso de descoberta dos signos que ainda desconhece e deseja conhecer. Podemos questionar o estudante sobre o que está aprendendo, mesmo sem termos a mínima noção do que está a estudar. Basta questionar sobre seu exercício e verificar o nível de "atenção" que colocou no que, a princípio, estudava e, em seguida, no momento de suas respostas às perguntas. Verificar a efetividade da pesquisa conduzida pelo estudante pode ser tarefa dirigida a qualquer um que se reconheça igual em inteligência a todos, decerto, basta-lhe que identifique o nível de "atenção" que se está colocando em cada signo que buscar conhecer. A "atenção" se traduz, por parte do estudante, em vigilância constante e rigorosa durante a "busca" individual. Desta forma, o estudante atento poderá perceber todos os signos novos que se apresentam no mundo e, fundamentalmente, associá-los aos seus signos para produzir novos signos: “O essencial é essa contínua vigilância, essa atenção que jamais se relaxa sem que venha a se instalar a desrazão - em que excelem tanto aquele que sabe quanto o ignorante." (RANCIÈRE, 2017, p. 57).

Para Rancière (2017), é possível fazer uma profunda reflexão acerca de nossas capacidades intelectuais em todos os campos de atuação humana. Nesse sentido, descobriremos as aptidões que nem ao menos desconfiamos que existam - se resume em um levantamento de nossas habilidades intelectuais, desta vez, desprezando a posição no mundo social que ocupamos. Para que isso seja possível, basta prestar "atenção incondicional” a todos os passos da atividade intelectual e perceber que não existem capacidades menores ou maiores de inteligência, mas ocorrências diferentes em cada indivíduo em todo o espaço de atuação humana.

\begin{tabular}{|l|l|l|l|l|}
\hline Rovista Dialectus & Ano 9 & n. 20 & Outubro - Novembro 2020 & p. 133-153
\end{tabular}


Para Rancière (2017, p. 61)

Permanece embrutecido aquele que opõe a obra das mãos operárias e do povo que nos alimenta às nuvens da retórica. A fabricação de nuvens é uma obra da arte humana que exige, nem menos, nem mais, tanto trabalho, tanta atenção intelectual quanto a fabricação de calçados e de maçanetas.

Não atingimos os nossos objetivos por falta de capacidade intelectual de nossa parte, mas, simplesmente, porque não empregamos a devida "atenção" àquela atividade:

A atenção não é nem uma bossa do cérebro, nem uma qualidade oculta. E um fato imaterial em seu princípio e material em seus efeitos: temos mil e um meios de verificar sua presença, sua ausência ou sua maior ou menor intensidade. E para isso que tendem todos os exercícios do Método Universal. (RANCIÈRE, 2017, p. 78).

O espírito humano é formado da união entre a vontade e a inteligência presente em cada homem e mulher e basta que a inteligência se dispense, se distraia para que o espírito seja levado pela gravitação da matéria, caia na desrazão, "[...] uma atividade da vontade pervertida, possuída pela paixão da desigualdade" (RANCIÈRE, 2017, p. 118). A ausência de "atenção" provoca a distração e, consequentemente, a interrupção do bom caminho das descobertas individuais:

Eis porque alguns filósofos e teólogos explicam o pecado original como uma simples distração. Nesse sentido, podemos dizer com eles que o mal não é mais do que ausência. Mas sabemos, também, que essa ausência é uma recusa. Aquele que se distrai não vê por que razão deveria prestar atenção. A distração é, de início, preguiça, desejo de subtrair-se ao esforço. A própria preguiça não é, todavia, torpor da carne, ela é ato de um espírito que subestima sua própria potência. (RANCIÉRE, 2017, p. 114).

A "atenção" se constitui como um dos elementos mais importantes no que diz respeito à tomada de consciência da igualdade de inteligência dos homens. Ter "atenção" no momento da leitura dos signos do mundo possibilita perceber a potência subestimada que todos os seres humanos possuem, mas desconhecem. Sendo assim, podemos utilizar o fator da "atenção" como um dos elementos possíveis para conduzir uma avaliação-verificação baseada nos princípios da "igualdade de inteligência" e "emancipação intelectual", presentes em $O$ mestre ignorante.

Outro elemento importante para a verificação da aprendizagem do estudante é a "busca". Para Rancière (2017), o mestre que ignora também se mantém vigilante em sua verificação da constante "busca" do estudante e, sobretudo, se mantém atento para não deixar

\begin{tabular}{|l|l|l|l|l|}
\hline Rovista Dialectus & Ano 9 & n. 20 & Outubro - Novembro 2020 & p. 133-153
\end{tabular}


que esse estudante pare de "buscar". A forma de instruir do mestre que ignora é verificar o quanto de "busca" o estudante está fazendo para aprender tudo que queira: "O mestre é aquele que mantém o que busca em seu caminho, onde está sozinho a procurar e o faz incessantemente". (RANCIÈRE, 2017, p. 57). No Ensino Universal, não buscamos encontrar explicações pormenorizadas em cada coisa, signo ou língua que se apresenta a nossa frente no mundo. Como indivíduos emancipados, o que realmente buscamos é aprender, à nossa medida, a inteligência daquele que escreveu, esculpiu, pintou, etc. e comparar sua manifestação intelectual com a nossa. Só assim, estaremos verificando a hipotética ideia da igualdade intelectual como princípio de ação no processo de ensino-aprendizagem. O que realmente devemos buscar fazer no ensino-aprendizagem é contra-traduzir os signos anteriormente traduzidos por outros homens e relacioná-los aos nossos signos e, acima de tudo, emitir novos signos que possam novamente produzir outras leituras (RANCIÈRE, 2017).

De acordo com o Ensino Universal, qualquer homem, por força de sua vontade, pode decifrar qualquer signo produzido por outro homem, desde que estabeleça a igualdade intelectual como princípio de sua ação de aprendizado: "Nada há aquém dos textos, a não ser a vontade de se expressar, isto é, de traduzir" (RANCIÈRE, 2017, p. 27). A união das vontades dos indivíduos com a necessidade do momento estimula o aparecimento de habilidades ainda não experimentadas. Segundo Rancière (2017), no ato de ensinar e aprender existem duas vontades: a vontade do estudante e a do mestre. Sendo assim, em uma situação hipotética estudante poderá estar ligado a uma vontade (mestre, mãe, pai, etc.), e deverá estar conectado à inteligência da "coisa comum". Quando a vontade do estudante está ligada à vontade do mestre e, da mesma forma, a inteligência do estudante está ligada à inteligência do mestre, ocorre o "embrutecimento" do estudante. Em contrapartida, quando a vontade do estudante está ligada à vontade do mestre, mas a inteligência não está, quando não há coincidência de inteligências, mas apenas de vontades, dá-se a "emancipação". Nisso, o estudante se percebe capaz, conhece sua potência intelectual e faz uso guiado, quando necessário, pela vontade do mestre. Ao contrário do sistema explicador, que parte da desigualdade das inteligências e se efetiva em grupo, o Ensino Universal se caracteriza por implantar, como hipótese, o princípio da igualdade das inteligências e a necessidade da emancipação intelectual (RANCIÈRE, 2017). O estudante não precisa da inteligência do mestre para interpretar os signos ou transpor as barreiras do aprender. Porém, a presença do mestre no processo de ensino-aprendizagem se faz necessária pois é, em grande medida, dele que parte o estímulo e a verificação das vontades distraídas para que os estudantes coloquem mais “atenção" na própria "busca”. Rancière (2017, 
p. 31), nesse sentido, afirma: "O homem — e a criança, em particular — pode ter necessidade de um mestre quando sua vontade não é suficientemente forte para colocá-la e mantê-la em seu caminho. Mas a sujeição é puramente de vontade a vontade".

Os adeptos do Ensino Universal devem entender que a "vontade", na qualidade de força que impulsiona os indivíduos a executar algo, é o motor da inteligência, sem a qual, a inteligência pode parar e sucumbir a desatenção das leis da matéria: "Resumamos essas observações, e diremos: o homem é uma vontade servida por uma inteligência. Talvez o fato de vontades desigualmente imperiosas seja suficiente para explicar a desigualdade das performances intelectuais" (RANCIÈRE, 2017, p. 79-80). A vontade é a potência que faz os homens andarem em busca do que almejam. É uma faculdade própria de cada homem, não podemos enxergá-la, apenas sentir e, acima de tudo, verificar sua presença em cada ação executada por uma inteligência: "Tenho sensações quando me apraz: ordeno a meus sentidos fornece-las. Tenho idéias (sic.) quando quero: ordeno a minha inteligência buscá-las, tatear. [...]. O homem é uma vontade servida por uma inteligência. (RANCIÈRE, 2017, p. 84).

Quando existe a ausência da vontade por parte do estudante, a inteligência peca e erra. A produção de atos do intelecto só pode acontecer quando existe vontade ou reflexão. É preciso dizer que o exercício da inteligência é ver e repetir (RANCIÉRE, 2017). De fato, se constitui em um trabalho árduo e enfadonho que, a depender do estudante, em muitos casos, pode causar preguiça, levar à distração e, consequentemente, ao erro. Rancière (2017, p. 85) afirma:

[...] que a palavra se carrega ou se esvazia de acordo com a vontade, que contrai ou relaxa a ação da inteligência. A significação é obra de vontade. Esse é o segredo do Ensino Universal. É também esse o segredo daqueles que são chamados gênios: o trabalho incessante para dobrar o corpo aos hábitos necessários, para ordenar à inteligência novas idéias (sic.), novas maneiras de exprimi-las; para refazer intencionalmente o que o acaso produziu e transformar circunstâncias infelizes em boas ocasiões de sucesso [...].

A escrita de um texto, o processo de lapidação de uma pedra preciosa e a confecção de um vestido são, sem exceção, manifestações do intelecto humano; são leituras feitas individualmente dos signos do mundo por indivíduos dotados de inteligência, impulsionados por força de suas vontades que, por sua vez, se materializam em forma de livros, joias e roupas. Não existe diferença na capacidade intelectual empregada em cada uma dessas produções humanas, apenas níveis de emprego do elemento da vontade. A vontade em sua ação tenta initerruptamente "comunicar" e "adivinhar", quase que simultaneamente, os signos

\begin{tabular}{|c|c|c|c|c|}
\hline Qonista Dialectus & Ano 9 & n. 20 & Outubro - Novembro 2020 & p. $133-153$ \\
\hline
\end{tabular}


interpretados por outras vontades sem o auxílio de intermediários e suas explicações intermináveis: “Toda palavra, dita ou escrita, é uma tradução que só ganha seu sentido na contra-tradução [...]" (RANCIÈRE, 2017, p. 95). Dessa forma, a produção feita por um ser humano que se reconhece igual intelectualmente a todos os outros ganha sentido no instante da contra-tradução feita por outro ser humano que, assim como o primeiro, se considera intelectualmente igual a todos os outros:

O pensamento não se diz em verdade, ele se exprime em veracidade. Ele se divide, ele se relata, ele se traduz por um outro que fará, para si, um outro relato, uma outra tradução, com uma única condição: a vontade de comunicar, a vontade de adivinhar o que o outro pensou e que nada, afora seu relato, garante, que nenhum dicionário universal explica como deve ser entendido. A vontade adivinha a vontade. É nesse esforço comum que toma sentido a definição de homem como uma vontade servida por uma inteligência. (RANCIÈRE, 2017, p. 93).

O espírito é a união entre a vontade e a inteligência e ao espírito podemos acrescer dois atributos: atenção e distração. (RANCIÈRE, 2017). A paixão que os homens nutrem pela desigualdade causa a distração da inteligência e, consequentemente, conduz ao governo da desrazão. Nesse sentido, o que perverte a vontade é acreditar na desigualdade como princípio: “A paixão pela desigualdade é a vertigem da igualdade, a preguiça diante da enorme tarefa que ela requer, o medo diante de um ser racional que se respeita a si próprio." (RANCIÈRE, 2017, p. 116).

Os homens idealizam a sociedade para se guardarem dos outros homens, decerto, querem a proteção contra a possível violência emanada daquela "paixão primitiva" pela desigualdade que coloca sempre em posição de disputa todos os homens contra todos os homens: “Assim, o mundo social não é apenas o mundo da não-razão, mas o da desrazão, isto é, de uma atividade da vontade pervertida, possuída pela paixão da desigualdade." (RANCIÈRE, 2017, p. 118). Mas, longe de ser um combate físico, se constitui em uma guerra como "ato de palavra". Nessa linha, a "[...] palavra recusa a aura de ideias irradiantes do contratradutor suscitado por uma outra inteligência ou por um outro discurso".

$\mathrm{Na}$ “distração", a "vontade pervertida" direciona a inteligência "[...] a só ver o que concorre para a preponderância, o que serve para anular outra inteligência.” (RANCIÈRE, 2017, p. 118-119). Ainda sobre a "desrazão" acrescentamos com Rancière (2017, p. 19) que

O universo da desrazão social é feito de vontades servidas por inteligências. No entanto, cada uma dessas vontades dá por sua missão destruir uma outra vontade, impedindo a outra inteligência de ver. E sabemos que este resultado não é muito difícil

\begin{tabular}{|c|c|c|c|c|}
\hline Q Ponista Dialectus & Ano 9 & n. 2 & Outubro - Novembro 2020 & p. $133-153$ \\
\hline
\end{tabular}


de se obter. Basta deixar agir a radical exterioridade da ordem da língua em relação à ordem da razão.

Por outro lado, existe a "vontade razoável" que, por força da "atenção", ligação mesmo que distante com a verdade e com forte desejo de falar ao outro como a um igual, mantém a inteligência em seu caminho de tradução e contratradução dos signos emanados de outras traduções de outras inteligências: “A vontade razoável, como vimos, é antes de qualquer coisa a arte de se vencer a si próprio. A razão se conservará fiel, controlando seu próprio sacrifício.” (RANCIÈRE, 2017, p. 131). Ressaltamos a importância que o uso atento da razão possui para se manter ativo no mundo da desrazão: “A razão vê tudo como é; ela mostra, ela esconde dos olhos tanto quanto julga conveniente, nem mais, nem menos." (RANCIÈRE, 2017, p. 135). A inteligência que é conduzida por uma "vontade atenta" poderá fazer uso da razão para escapar das amarras da paixão pela desigualdade que prendem os homens no ambiente da desrazão e "Aquele que sabe permanecer fiel a si em meio à desrazão, exercerá sobre as paixões do outro o mesmo domínio que exerce sobre as suas." (RANCIÈRE, 2017, p. 135-136). Decerto, importa dizer que mesmo preso em um ambiente social, ou melhor, da desrazão, o razoável desrazoante pode fazer uso do poder da razão para entender que os códigos ali apresentados servem não para “[...] persuadir os espíritos, mas distraí-los.” (RANCIÈRE, 2017, p. 134).

Dessa forma, Rancière (2017, p. 135) afirma que:

Preso ao círculo da loucura social, o razoável desrazoante demonstra que a razão do indivíduo jamais cessa de exercer seu poder. No campo fechado das paixões — dos exercícios da vontade distraída - é preciso mostrar que a vontade atenta sempre pode o que elas podem - e ainda mais.

Percebemos que a "vontade atenta" pode descortinar, inventariar e fazer bom uso da razão, mesmo que a inteligência esteja presa em um mundo social de explicadores/as. Aquele/a que não busca repetir e aprender outra arte fará o mesmo que Sócrates fez em seu julgamento: permaneceu desatento ao se utilizar do "desejo primitivo" do ser humano pela desigualdade das inteligências; abdicou levianamente de fazer uso de sua "vontade atenta" e sucumbiu no "exercício da vontade distraída":

Sócrates não quis fazer um discurso para agradar ao povo, para seduzir a 'grande besta'. Ele não quis estudar a arte dos sicofantas Anitos e Meletos. Ele pensou, e quase todos o louvam por tal, que isso equivaleria a permitir, em sua pessoa, a decadência da filosofia. Mas o fundo de sua opinião é: Anitos e Meletos são sicofantas imbecis; não há, portanto, nenhuma arte em seu discurso, somente uma espécie de cozinha. 
Não há aí o que aprender. Ora, os discursos de Anitos e Meletos são uma manifestação da inteligência humana, ao mesmo título do que os de Sócrates. Não estamos afirmando que são tão bons. Diremos, apenas, que procedem da mesma inteligência. Sócrates, o 'ignorante', se imaginou, quanto a ele, superior aos oradores de tribunal, teve preguiça de aprender sua arte e consentiu com a desrazão do mundo. (RANCIÈRE, 2017, p. 136-137, grifo do autor).

Avaliando essa passagem a partir dos elementos da "busca", "atenção" e "vontade" de $O$ mestre ignorante (2017), compreendemos que Sócrates não prestou atenção na singularidade dos signos que se apresentaram a sua frente, na verdade, não percebeu e, sendo assim, também não compreendeu a necessidade daquele instante de decodificar a língua dos sicofantas. Ele, a sua maneira, não tentou buscar contra-atraduzir o signo que se manifestava naquele instante a sua frente, simplesmente, abdicou de tentar entender tudo aquele momento. Certamente, não utilizou o elemento da vontade para impulsionar sua inteligência para, simultaneamente, adivinhar e comunicar as descobertas dos signos. De fato, não enxergou como seres humanos iguais em inteligência os seus acusadores. Talvez, por isso, tenha sido oferecido a ele o "direito de escolha" de penas tão duras.

\section{CONSEDERAÇÕES FINAIS}

Os recortes aqui apresentados retratam a busca em tentar entender o processo de ensino-aprendizagem no componente curricular de Filosofia no Ensino Médio público, com ênfase, na parte da avaliação. Optamos em caminhar discutindo esse tema na companhia de $O$ mestre ignorante. A experiência emancipatória de Jacotot nos indicou um percurso a seguir e, substancialmente, possibilitou indicações para dar início a essa procura. Desta forma, propomos uma ação educativa-filosófica estruturada a partir dos signos "igualdade de inteligência" “emancipação intelectual” presente em $O$ mestre ignorante. Distante de elaborar mais um método institucionalizado para ensinar Filosofia, comprovadamente ineficaz e combatido por Jacotot, pesamos em indicar oito princípios educacionais-filosóficos que poderiam propiciar uma aprendizagem emancipatória. No último passo falamos em uma avaliação que se distancia da mensuração dos conteúdos e, eventualmente, se aproxima da verificação da atitude do estudante em tentar descobrir/interpretar os signos do mundo. Estamos falando de uma estrutura de avaliação em Filosofia baseada na ação, em um movimento feito individualmente na tentativa de conhecer as coisas do mundo sem intermediários. Sendo assim, elegemos três elementos que podem ser utilizados para verificar a existência e a constância desse movimento intelectual feito pelos seres humanos: "atenção", "busca" e "vontade". Em qualquer caminho

\begin{tabular}{|c|c|c|c|c|}
\hline Gonista Dialectus & Ano 9 & n. 20 & Outubro - Novembro 2020 & p. $133-153$ \\
\hline
\end{tabular}


intelectual, baseado na igualdade e na emancipação, o mestre procura encontrar esses três elementos nas ações/atitudes dos estudantes.

Por fim, como a pesquisa dissertativa já foi defendida, cabe-nos dizer que utilizar das lições de $O$ mestre ignorante (RANCIÈRE, 2017) para traçar um caminho para o ensinoaprendizagem de Filosofia na Escola básica e, consequentemente, repensar o papel da avaliação nesse mostrou que a ação educativa-filosófica realizada na Escola possibilitou aos estudantes aprender sobre a estrutura de ensino-aprendizagem da Filosofia no nível médio, sobre os papéis dos principais personagens do processo educacional, reavaliar a relação com os mecanismos da avaliação e, sem esquecer, que viabilizou aos participantes da pesquisa a possibilidade de perceber, cada um à sua medida, alguns aspectos de suas capacidades intelectuais.

\section{Referências}

ABBAGNANO, Nicola. Dicionário de Filosofia. Tradução de Alfredo Bosi. 4. ed. São Paulo. Martins Fontes, 2000.

BOAVIDA, João. Por uma didáctica para a filosofia - análise de algumas razões. In: Revista Filosófica de Coimbra, n. 9, 1996. p. 91-110. Disponível em: https://www.saavedrafajardo.org/Archivos/Coimbra/09/Coimbra09-04.pdf. Acesso em: 04 maio 2020.

CEPPAS, Filipe. Arte, educação e emancipação. In: Aisthe, v. VII, n. 11, p. 89-101, 2013.

CERLETTI, Alejandro. La política ignorante del maestro de escuela: la lección de Rancière. In: Educ. Soc., v. 24, n. 82, p. 299-308, abr. 2003.

CERLETTI, Alejandro. O ensino de filosofia como problema filosófico. Tradução de Ingrid Muller Xavier. Belo Horizonte: Autentica Editora, 2009.

CRUZ, Crislaine Santana; BRETAS, Silvana Aparecida. O Método da Igualdade: Jacotot e a experiência do ensino universal no contexto da Revolução Francesa. In: Reunião Nacional da ANPEd, 38. Anais [...]. São Luís, MA: UFMA, out. 2017. p. 1-17. Disponível em: http://anais.anped.org.br/sites/default/files/arquivos/trabalho_38anped_2017_GT02_846.pdf.

Acesso em: 21 jul. 2019.

KOHAN, Walter Omar. Infância - entre educação e filosofia. Belo Horizonte: Autêntica, 2005.

MARQUES, Ângela Cristina Salgueiro; PRADO, Marco Aurélio Máximo. O Método da Igualdade em Jacques Rancière: entre a política da experiência e a poética do conhecimento. In: Revista Mídia e Cotidiano, v. 12, n. 3, p. 7-32, dez. 2018.

RANCIÈRE, Jacques. Atualidade de $O$ mestre ignorante. [Entrevista cedida a] VERMEREN, Patrice, CORNU, Laurence e BENVENUTO, Andrea. Educ. Soc., v. 24, n. 82, p. 185-202, abr. 2003. 
RANCIÈRE, Jacques. O mestre ignorante - cinco lições sobre a emancipação intelectual. Tradução de Lilian do Valle. 3. ed. Belo Horizonte: Autêntica Editora, 2017. 